\title{
Role of mean platelet volume in hypertriglyceridemia-induced acute pancreatitis during pregnancy
}

\author{
Longhuan Zeng ${ }^{\dagger}$, Xueying Cai ${ }^{\dagger}$, Jiayi Chen, Guangyong Jin and Yongke Zheng ${ }^{*}$
}

\begin{abstract}
Background: Hypertriglyceridemia-induced acute pancreatitis during pregnancy (HTG-APP) is a rare but severe disease with high maternal-fetal mortality risk, which constitutes a systemic inflammatory process accompanied by thrombosis and bleeding disorders. However, the role of mean platelet volume (MPV) in HTG-APP remains unclear.

Methods: In the retrospective study, we collected 45 patients with HTG-APP as the HTG-APP group and 49 pregnant females with hypertriglyceridemia as the control group. MPV and other relevant variables at onset and remission were collected and compared.

Results: MPV were significantly higher in the HTG-APP group than in the control group $(P<0.001)$, and lower in remission than on onset $(P=0.002)$. According to the severity of acute pancreatitis, all subjects were classified into mild AP (MAP), moderately severe AP (MSAP), and severe AP (SAP) groups. There was a significant difference in MPV on onset among the three groups $(P=0.048)$, and the SAP patients had the highest levels of MPV. In addition, only in the SAP group, MPV was lower in remission than on onset $(P=0.010)$. Logistic regression analyses revealed that MPV was significantly associated with SAP (odds ratio $=2.077,95 \%$ confdence interval, $1.038-4.154 ; P=0.039$ ).

Conclusions: These results may indicate an important role of mean platelet volume in evaluating the severity of HTG-APP.
\end{abstract}

Keywords: Hypertriglyceridemia-induced acute pancreatitis, Pregnancy, Mean platelet volume, Diagnosis, Severity

\section{Background}

Acute pancreatitis during pregnancy (APP) is a rare, but life-threatening disease with an estimated incidence of approximately $3-10 / 10,000[1,2]$. AP can result in multiple organ dysfunction and disseminated intravascular coagulation owing to activation of the inflammatory and coagulation systems. Moreover, pregnancy-related physiologic alterations influence the diagnosis and management of many diseases. Therefore, APP can severely

\footnotetext{
* Correspondence: hzsymedical@163.com

'Longhuan Zeng and Xueying Cai contributed equally to the study Department of Intensive Care Unit, Affiliated Hangzhou First People's Hospital, Zhejiang University School of Medicine, 261 Huansha Road, 310006 Hangzhou, Zhejiang, China
}

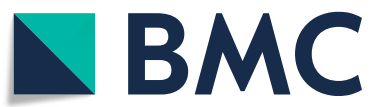

(c) The Author(s). 2020 Open Access This article is licensed under a Creative Commons Attribution 4.0 International License, which permits use, sharing, adaptation, distribution and reproduction in any medium or format, as long as you give appropriate credit to the original author(s) and the source, provide a link to the Creative Commons licence, and indicate if changes were made. The images or other third party material in this article are included in the article's Creative Commons licence, unless indicated otherwise in a credit line to the material. If material is not included in the article's Creative Commons licence and your intended use is not permitted by statutory regulation or exceeds the permitted use, you will need to obtain permission directly from the copyright holder. To view a copy of this licence, visit http://creativecommons.org/licenses/by/4.0/ The Creative Commons Public Domain Dedication waiver (http://creativecommons.org/publicdomain/zero/1.0/) applies to the data made available in this article, unless otherwise stated in a credit line to the data.

affect the mother and fetus and lead to a higher risk of intrauterine fetal death.

The most common cause of APP is gallstones, followed by alcohol abuse, hypertriglyceridemia, and unknown causes [3]. Non-gallstone pancreatitis is thought to be related to more complications and a poorer prognosis, such as hypertriglyceridemia-induced AP (HTG-AP) [4].

Mean platelet volume (MPV) is a blood parameter used for measuring platelet size and is accepted as a widely used indicator of thrombocytic activity. In addition, MPV has been investigated in various thrombotic and inflammatory diseases [5].

To date, there have been few studies reporting the association between MPV and AP, and the results have 
been inconsistent [6-9]. Furthermore, fewer reports have focused on the relationship between MPV and HTG-AP during pregnancy (HTG-APP), and the role of MPV is unclear in this population. Therefore, we designed the current study to assess the role of MPV and the potential relationship with disease severity in HTG-APP.

\section{Methods}

\section{Ethical approval of the study protocol}

This study complied with the Declaration of Helsinki [10] and was approved by the Ethics Committee of Hangzhou First People's Hospital. All patients enrolled in the study submitted written informed consent.

\section{Patient enrollment}

In this retrospective study, we collected 45 patients with HTG-APP (HTG-APP group). The patients were hospitalized in the intensive care unit (ICU) at Hangzhou First People's Hospital (Hangzhou, China) from January 2010 to December 2018. As a control group, 49 consecutive pregnant females with hypertriglyceridemia were included. Patients who had biliary AP, idiopathic AP, alcohol intake, trauma, preexisting chronic pancreatitis, and a history of AP were excluded from the study. This study was approved by the Ethics Committee of Hangzhou First People's Hospital and complied with the ethical standards.

Based on the Chinese guidelines for AP and HTG-AP, patients with AP who had a triglycerides level $\geqq$ $11.3 \mathrm{mmol} / \mathrm{L}(1000 \mathrm{mg} / \mathrm{dl})$ or between 5.65 and $11.3 \mathrm{mmol} / \mathrm{L}$ (500-1000 mg/dl), but with lipemic serum after excluding gallstone, alcohol, or medication factors, were diagnosed with HTG-AP [11].

The severity of AP was classified according to the 2012 revised Atlanta Classification, as follows: mild AP (MAP), patients without organ failure and without local complications; moderately severe AP (MSAP), patients with organ failure for $<48 \mathrm{~h}$ or local complications; and severe AP (SAP), patients with organ failure for $>48 \mathrm{~h}$ [12]. All patients were categorized into the following three groups: MAP, MSAP, and SAP. Since the main purpose of this study was to distinguish SAP in the early stage of the disease, MSAP and MAP were merged with the NonSAP group, while AP with SAP was considered the SAP group. We defined gestational age as the first (before 12 weeks), second (13-27 weeks), and third trimesters (28 weeks until delivery).

\section{Data collection}

The first day of hospitalization in the ICU was designated as the onset, and the day that a patient was discharged from the ICU was designated as remission when the clinical symptoms and biochemical tests were normal. Clinical data, including the age, gestational age,
Ranson score, medical history, complications, and treatment were collected. Laboratory indicators, including the white blood cell (WBC) count, platelet count, MPV, hematocrit, high-sensitivity C-reactive protein (hs-CRP), total bilirubin, alanine aminotransferase (ALT), aspartate aminotransferase (AST), albumin, lactate dehydrogenase (LDH), triglycerides, total cholesterol (TC), glucose, creatinine, amylase, calcium, and D-dimer, were measured and collected at the onset. Except for the control group, the platelet count, MPV, and D-dimer were collected in remission.

\section{Statistical analysis}

The Kolmogorov-Smirnov test was utilized for estimating the compatibility of normally distributed data. Continuous data were expressed as the mean \pm standard deviation or median and $25^{\text {th- }} 75$ th percentiles as appropriate. All normally-distributed data were compared

Table 1 Baseline characteristics in patients with HTG-APP $(n=45)$

\begin{tabular}{ll}
\hline Variables & Value \\
\hline During in ICU (days) & $5.36 \pm 4.18$ \\
Ranson score, median (range) & $1(0-3)$ \\
Trimester (n, \%) & \\
First & $3(6.7 \%)$ \\
Second & $11(24.4 \%)$ \\
Third & $31(68.9 \%)$ \\
Comorbidity (n, \%) & \\
Fatty liver & $11(24.4 \%)$ \\
Gestational diabetes mellitus & $5(11.1 \%)$ \\
Pregnancy-induced hypertension & $2(4.4 \%)$ \\
Local complications (n, \%) & \\
Acute necrotic collections & $6(13.3 \%)$ \\
Walled-off pancreatic necrosis & $14(31.1 \%)$ \\
Acute peripancreatic fluid collections & $1(2.2 \%)$ \\
Pancreatic pseudocyst & $8(17.8 \%)$ \\
Systemic complications (n, \%) & \\
Circulatory failure & $5(11.1 \%)$ \\
Respiratory failure & $12(26.7 \%)$ \\
Renal failure & $4(8.9 \%)$ \\
Ketoacidosis & $8(17.8 \%)$ \\
Mortality (n, \%) & \\
Mother & $1(2.2 \%)$ \\
Foetus & $6(13.3 \%)$ \\
Treatment $(n, \%)$ & $11(24.4 \%)$ \\
Plasma exchange & $16(35.6 \%)$ \\
\hline
\end{tabular}


using independent samples or paired Student's t-tests. Data shown to be non-normally distributed were analyzed using the Mann-Whitney U test or the Wilcoxon rank-sum test. Multi-group comparisons were made using one-way ANOVA or the Kruskal-Wallis $\mathrm{H}$ test, depending on the distribution of variables. Logistic regression analysis was used to determine the relationship between MPV as well as other clinical data andHTGAPP severity. In the model, SAP is defined as dependent variable, and we entered MPV, triglyceride as well as those variables with significant differenes at a $P$-value $<$ 0.05 and in backward wald fashion. For all tests, a twotailed $P$-value $<0.05$ was considered statistically significant. All calculations were performed using SPSS (version 16.0 for Windows; IBM, Armonk, NY, USA).

\section{Results}

Forty-five patients with HTG-APP and 49 control subjects were enrolled in the present study. Of the 45 pregnant women with HTG-AP, the mean gestational age was $31.22 \pm 6.65$ weeks, with most of the cases occurring in the third trimester (69\%). MAP was diagnosed in $38 \%(n=17)$ of the patients, MASP in $29 \%(n=13)$, and SAP in $33 \%(n=15)$. The clinical characteristics, complications, and treatment of study participants are summarized in Table 1 . One patient with SAP died during the ICU stay.

Table 2 shows that there were no significant differences in age, gestational age, platelet count, ALT, AST, total bilirubin, and creatinine between the HTG-APP and control groups (all $P>0.05$ ).

Patients with HTG-APP had a significantly higher length of hospital stay than the control group $(P<$ $0.001)$. The WBC $(P<0.001)$, hs-CRP $(P<0.001)$, glucose $(P<0.001)$, TC $(P<0.001)$, triglycerides $(P<0.001)$, HDL-C $(P=0.034)$, LDL-C $(P<0.001)$, LDH $(P<0.001)$, amylase $(P<0.001)$, and D-dimer $(P<0.001)$ levels were significantly higher in the HTG-APP patients than the control group, whereas serum calcium $(P<0.001)$ and hematocrit $(P=0.005)$ levels in the HTG-APP group were significantly lower than those in the control group (Table 2).

A statistically significant increase in MPV levels was observed in patients with HTG-APP compared with the control group $(11.29 \pm 1.47$ vs. $10.01 \pm 1.54, P<0.001$, Table 2). Figure 1 shows that the mean MPV values of HTG-APP patients at onset and in remission compared with controls.

Table 2 Demographic characteristics and laboratory values of the patients and controls

\begin{tabular}{|c|c|c|c|}
\hline Variables & HTG-APP $(n=45)$ & Control $(n=49)$ & $\mathbf{P}$ \\
\hline Age (years) & $29.36 \pm 4.75$ & $28.61 \pm 4.77$ & 0.451 \\
\hline Gestational age (weeks) & $31.22 \pm 6.65$ & $29.92 \pm 9.06$ & 0.432 \\
\hline During in hospital (days) & $21.30 \pm 14.53^{*}$ & $6.41 \pm 5.68$ & $<0.001$ \\
\hline WBC $\left(\times 10^{9} / \mathrm{L}\right)$ & $15.26 \pm 4.82^{*}$ & $9.07 \pm 2.94$ & $<0.001$ \\
\hline Hematocrit (\%) & $31.78 \pm 5.18^{*}$ & $34.57 \pm 4.29$ & 0.005 \\
\hline Platelet $\left(\times 10^{9} / \mathrm{L}\right)$ & $189.98 \pm 72.23$ & $203.45 \pm 56.83$ & 0.316 \\
\hline MPV (fL) & $11.29 \pm 1.47^{*}$ & $10.01 \pm 1.54$ & $<0.001$ \\
\hline $\mathrm{HS}-\mathrm{CRP}(\mathrm{mg} / \mathrm{L})$ & $111.00(62.00-160.00)^{*}$ & $5.00(3.00-11.50)$ & $<0.001$ \\
\hline $\mathrm{ALT}(\mathrm{U} / \mathrm{L})$ & $18.00(12.00-26.57)$ & 19.00 (12.00-33.50) & 0.279 \\
\hline AST (U/L) & $19.00(19.00-28.50)$ & $23.00(17.00-32.36)$ & 0.136 \\
\hline Total bilirubin $(\mu \mathrm{mol} / \mathrm{L})$ & $11.00(7.50-16.70)$ & $11.00(8.00-16.15)$ & 1.000 \\
\hline Albumin (g/L) & $32.46 \pm 7.90$ & $33.53 \pm 4.19$ & 0.410 \\
\hline Calcium (mmol/L) & $1.89 \pm 0.38^{*}$ & $2.28 \pm 0.55$ & $<0.001$ \\
\hline Creatinine $(\mu \mathrm{mol} / \mathrm{L})$ & $60.13 \pm 31.73$ & $56.98 \pm 12.81$ & 0.523 \\
\hline Glucose (mmol/L) & $7.72 \pm 4.45^{*}$ & $5.11 \pm 3.30$ & $<0.001$ \\
\hline Total cholesterol (mmol/L) & $22.81(13.52-37.81)^{*}$ & $6.09(4.91-8.55)$ & $<0.001$ \\
\hline Triglyceride (mmol/L) & $28.00(17.56-56.65)^{*}$ & $5.86(5.35-8.26)$ & $<0.001$ \\
\hline $\mathrm{HDL}-\mathrm{c}(\mathrm{mmol} / \mathrm{L})$ & $1.93(1.24-3.36)^{*}$ & $1.66(1.35-1.83)$ & 0.034 \\
\hline LDL-c (mmol/L) & $5.40(3.20-9.76)^{*}$ & $2.92(1.99-3.68)$ & $<0.001$ \\
\hline $\mathrm{LDH}(\mathrm{U} / \mathrm{L})$ & $260.00(189.00-398.50)^{*}$ & $173.00(148.00-206.50)$ & $<0.001$ \\
\hline Serum amylase (U/L) & $224.00(157.00-656.00)^{*}$ & $78.00(60.00-140.50)$ & $<0.001$ \\
\hline D-dimer $(\mu \mathrm{g} / \mathrm{L})$ & $2846.67(1916.11-4355.00)^{*}$ & $1857.97(1100.00-2182.00)$ & $<0.001$ \\
\hline
\end{tabular}

${ }^{*} P<0.05$, HTG-APP versus control 


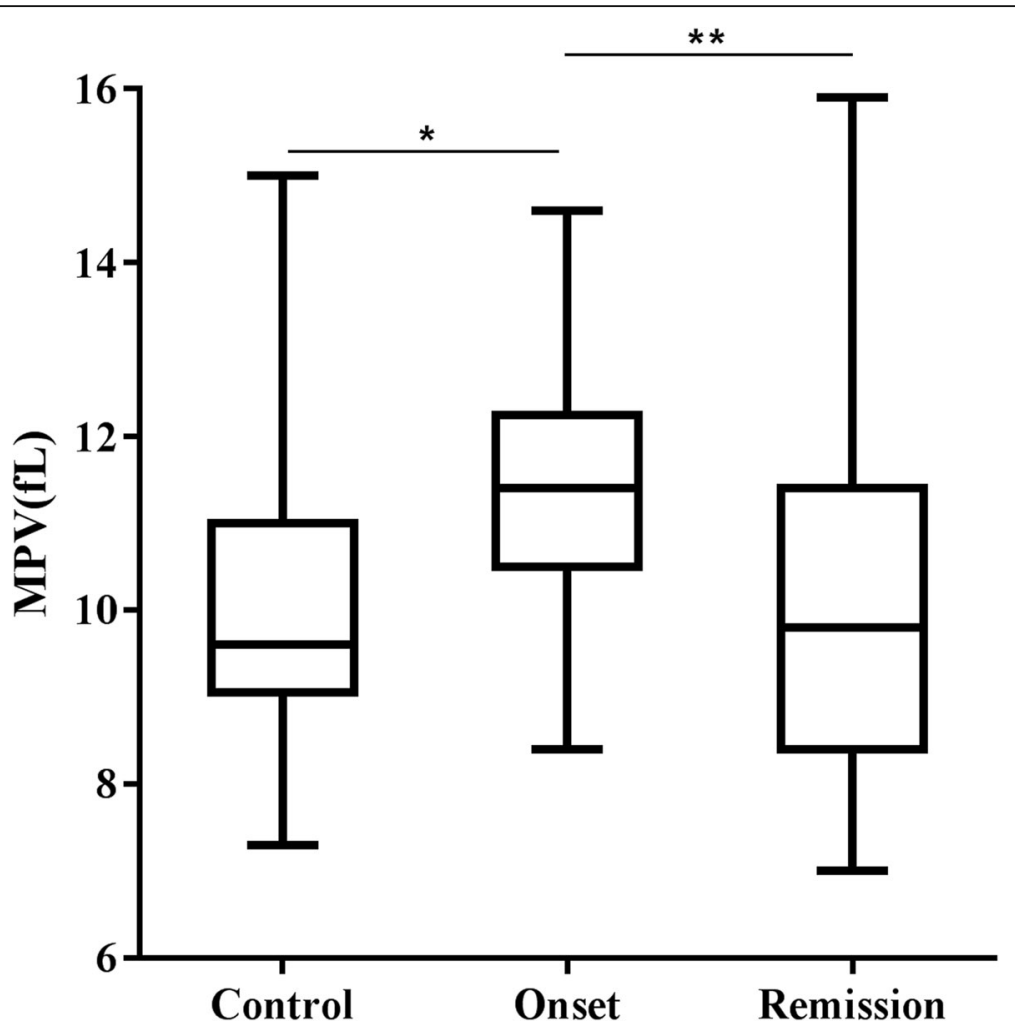

Fig. 1 MPV levels of the patients with HTG-APP(at onset and remission) and healthy controls. ${ }^{*} P<0.05$, Onset versus Control; ${ }^{* *} P<0.05$, Onset versus Remission

All HTG-APP patients were classified into SAP and Non-SAP groups. The MPV $(P=0.039)$, HS-CRP $(P=$ $0.003)$, AST $(P=0.030)$, glucose $(P=0.004)$, creatinine $(P=0.005)$, and total cholesterol $(P=0.025)$ levels were significantly higher in the SAP group than the Non-SAP group (Table 3). The patients at onset had higher mean MPV levels than patients in remission $(11.29 \pm 1.47 \mathrm{fL}$ vs. $10.10 \pm 2.03 \mathrm{fL}, P=0.002$, Table 4 ). Further analysis revealed a significant difference in MPV at onset among the three groups $(10.64 \pm 1.56 \mathrm{fL}, 11.48 \pm 1.42 \mathrm{fL}$ vs. $11.88 \pm 1.19 \mathrm{fL}, P=0.048)$, with the highest levels detected in the SAP patients $(11.88 \pm 1.19 \mathrm{fL}$, Table 4; Fig. 2). Differences in MPV in remission were not statistically significant among the three groups $(10.00 \pm 2.03$ $\mathrm{fL}, 10.16 \pm 2.09 \mathrm{fL}$ vs. $10.16 \pm 2.11 \mathrm{fL}, P=0.976$, Table 4$)$. There was also a significant difference between onset and remission in the SAP group $(P=0.010)$, but no significant differences were shown in the MAP and MSAP groups (all $P>0.05$, Table 4). In bivariate logistic regression analysis, the MPV level was independent associated with SAP (odds ratio $[\mathrm{OR}]=2.077,95 \%$ confdence interval $[\mathrm{CI}], 1.038-4.154 ; P=0.039$, Table 5).

\section{Discussion}

HTG-APP is a rare but severe disease with high maternal-fetal mortality risks, which presents as a systemic inflammatory process that is often accompanied by thrombosis and bleeding disorders. Normally, triglyceride levels rise gradually during pregnancy and reach a peak in the third trimester of gestation to 2-to4-fold over pre-pregnancy levels. In addition, high levels of estrogen related to pregnancy can reduce the activity of lipoprotein lipase and lead to hypertriglyceridemia [13] There is an increased risk for AP when serum triglyceride levels are $>10 \mathrm{~g} / \mathrm{L}(11.3 \mathrm{mmol} / \mathrm{L})$ [14], which is why most cases of HTG-AP occurred during the third trimester of gestation.

Currently, there are no standardized guidelines for clinicians regarding hypertriglyceridemia-induced AP during pregnancy. Moreover, the main diagnostic methods rely on clinical experience, and the existing serum biomarkers are helpful in assessing AP severity. Therefore, early, alternative, and easily applicable markers are needed.

It has been reported that platelet activation plays an important role in the development and evolution of AP [15]. MPV is a simple parameter showing platelet function and activation that can be measured by complete blood count analysis at no additional cost.

Abnormal MPV has been correlated with thrombotic and inflammatory conditions, such as myocardial infarction, acute cerebral ischemia, inflammatory bowel 
Table 3 Clinical Characterization of the patients with SAP and Non-SAP

\begin{tabular}{|c|c|c|c|}
\hline Variables & $\operatorname{SAP}(n=15)$ & Non-SAP $(n=30)$ & $\mathbf{P}$ \\
\hline Age (years) & $29.20 \pm 4.46$ & $29.43 \pm 4.97$ & 0.879 \\
\hline Gestational age (weeks) & $33.47 \pm 3.83$ & $30.10 \pm 7.47$ & 0.110 \\
\hline During in hospital (days) & $25.64 \pm 18.98$ & $19.27 \pm 11.76$ & 0.178 \\
\hline WBC $\left(\times 10^{9} / \mathrm{L}\right)$ & $16.48 \pm 6.44$ & $13.29 \pm 4.88$ & 0.070 \\
\hline Hematocrit (\%) & $32.17 \pm 7.46$ & $31.59 \pm 3.70$ & 0.729 \\
\hline Platelet $\left(\times 10^{9} / \mathrm{L}\right)$ & $181.53 \pm 85.75$ & $194.20 \pm 65.65$ & 0.585 \\
\hline MPV (fL) & $11.88 \pm 1.19^{*}$ & $10.95 \pm 1.47$ & 0.039 \\
\hline HS-CRP (mg/L) & $151.00(115.00-189.00)^{*}$ & 81.00 (39.25-144.25) & 0.003 \\
\hline $\mathrm{ALT}(\mathrm{U} / \mathrm{L})$ & $16.00(10.00-21.00)$ & $20.00(12.00-27.13)$ & 0.469 \\
\hline AST (U/L) & $27.00(20.00-37.00)^{*}$ & $17.78(17.00-22.00)$ & 0.030 \\
\hline Total bilirubin ( $\mu \mathrm{mol} / \mathrm{L})$ & $11.00(7.80-16.50)$ & $10.95(7.00-16.83)$ & 0.847 \\
\hline Albumin (g/L) & $29.76 \pm 5.72$ & $33.78 \pm 7.71$ & 0.081 \\
\hline Calcium (mmol/L) & $1.78 \pm 0.43$ & $1.95 \pm 0.34$ & 0.150 \\
\hline Creatinine $(\mu \mathrm{mol} / \mathrm{L})$ & $70.27 \pm 20.19^{*}$ & $52.63 \pm 18.15$ & 0.005 \\
\hline Glucose (mmol/L) & $8.69 \pm 3.04^{*}$ & $6.14 \pm 2.49$ & 0.004 \\
\hline Total cholesterol (mmol/L) & $35.37(20.29-49.50)^{*}$ & $20.21(11.30-33.05)$ & 0.025 \\
\hline Triglyceride (mmol/L) & $35.16(18.43-62.80)$ & $24.08(16.86-45.57)$ & 0.289 \\
\hline $\mathrm{HDL-c}(\mathrm{mmol} / \mathrm{L})$ & $3.00(1.47-3.60)$ & $1.85(1.14-2.71)$ & 0.198 \\
\hline LDL-c (mmol/L) & $5.77(3.64-8.30)$ & $4.85(2.91-10.24)$ & 0.914 \\
\hline LDH (U/L) & $238.00(213.00-277.00)^{*}$ & $205.50(184.50-248.00)$ & 0.053 \\
\hline Serum amylase (U/L) & $283.00(107.00-723.00)$ & 219.00 (160.00-486.50) & 0.962 \\
\hline D-dimer ( $\mu \mathrm{g} / \mathrm{L})$ & 4200.00 (2340.00-5720.00) & $2823.34(1607.50-3717.50)$ & 0.094 \\
\hline
\end{tabular}

${ }^{*} P<0.05$, SAP versus Non-SAP

disease, rheumatoid arthritis, and familial Mediterranean fever [16-20]; however, the relationship between MPV and AP has not been fully clarified, especially hypertriglyceridemia-induced SAP during pregnancy.

Our finding showed that MPV levels were increased in patients with HTG-APP compared with controls. Furthermore, MPV levels were increased with the severity of HTG-AP at onset and decreased during remission.

To date, several previous studies have investigated the relationship between AP and MPV, but the results were conflicting. Beyazit et al. [21] examined the role of MPV in AP and described a significant decrease in MPV in patients with AP compared with healthy subjects. Erbis et al. [9] in a study involving 76 patients with pancreatitis showed that patients with pancreatitis had lower levels in MPV, and the mean MPV values were lower in AP patients $(7.2 \pm 0.52 \mathrm{fL})$ than in AP $(7.9 \pm 0.53 \mathrm{fL})$. Another contemporaneous study reported that MPV was significantly lower on admission than during remission in biliary and non-biliary AP patients [9]. Recently, Lei et al. [22] also reported that MPV levels were significantly lower in the AP group than the control group, and MPV presented an upward trend during the first week after admission in all AP patients.

Although the previous results suggested low MPV levels in AP, these studies excluded patients who had

Table 4 MPV on onset and in remission in MAP, MASP and SAP group

\begin{tabular}{lllll}
\hline Variable Groups & & Onset & Remission & P (onset and remission) \\
\hline MPV & Total $(n=45)$ & $11.29 \pm 1.47^{*}$ & $10.10 \pm 2.03$ & 0002 \\
& MAP $(n=17)$ & $10.64 \pm 1.56$ & $10.00 \pm 2.03$ & 0.311 \\
MASP $(n=13)$ & $11.48 \pm 1.42$ & $10.16 \pm 2.09$ & 0.076 \\
SAP $(n=15)$ & $11.88 \pm 1.19^{*}$ s & $10.16 \pm 2.11$ & 0.010 \\
& P (MAP, MASP and SAP) & 0.048 & 0.976 & \\
\hline
\end{tabular}

*P $<0.05$, Onset versus Remission

${ }^{\S} P<0.05$, SAP, MASP versus MAP 


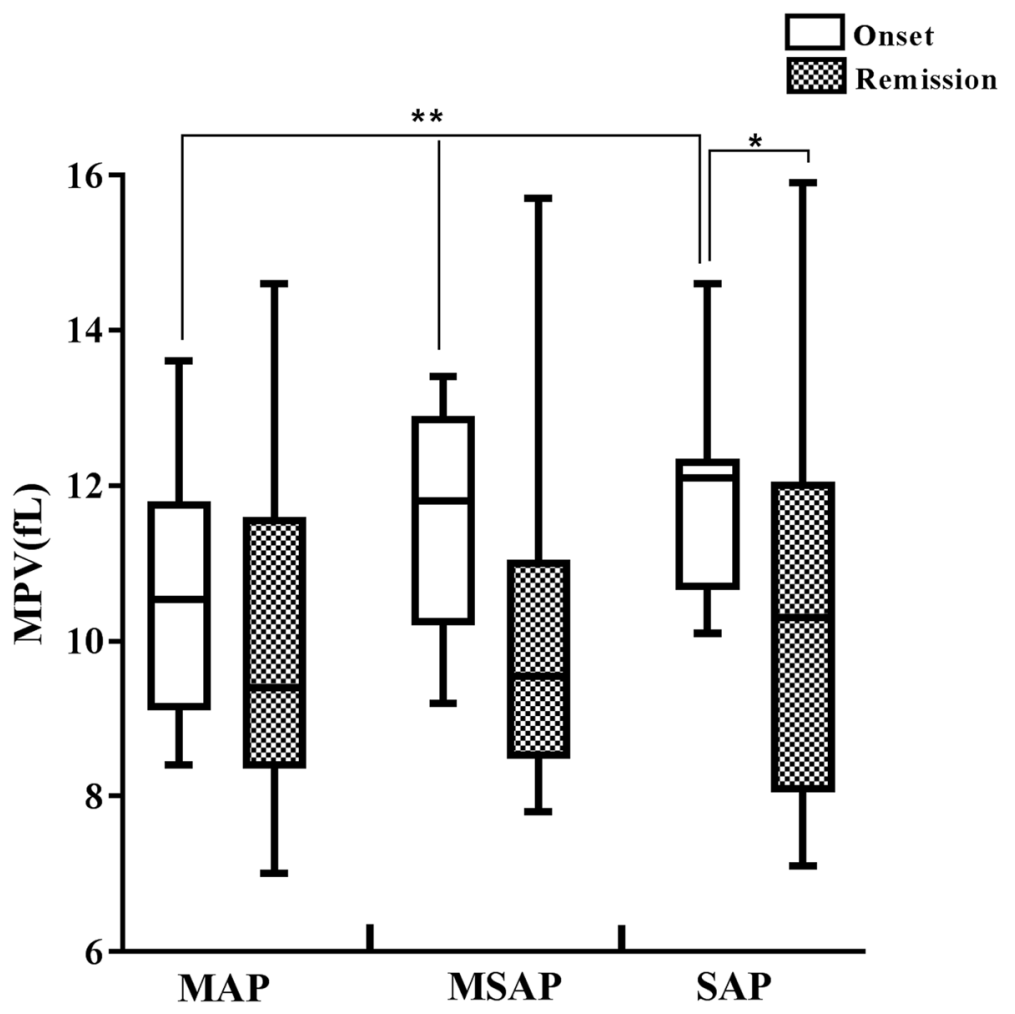

Fig. 2 MPV levels of the patients with MAP, MSAP and SAP. ${ }^{*} P<0.05$, Onset versus Remission.; ${ }^{*} P<0.05$, Onset versus Remission

pregnancy or hyperlipidemia. In comparison, we focused on patients with hyperlipidemia-induced AP in pregnancy. It is probable that the disparity in the studies may be explained by differences in the study population and design. Thus, we should pay more attention to further studies.

The exact reason for increased MPV in hyperlipidemia-induced SAP during pregnancy remains unknown, but it has been speculated that platelets not only control thrombosis and hemostasis, but also regulate inflammatory conditions. There is a stimulation of megakaryopoiesis in the early stages of the inflammatory process associated with hyperlipidemia-induced SAP, which produces a large amount of young and large platelets with high procoagulation potential [23]. Osada

Table 5 Bivariate logistic regression analyses of MPV, triglyceride as well as other clinical data and SAP in patients with HTG-APP

\begin{tabular}{lll}
\hline Variable & OR $(\mathbf{9 5} \% \mathbf{C l})$ & $\mathbf{P}$ \\
\hline MPV & $2.077(1.038-4.154)$ & 0.039 \\
Glucose & $1.406(1.035-1.908)$ & 0.029 \\
HS-CRP & $1.000(0.987-1.014)$ & 0.987 \\
Triglyceride & $1.023(1.000-1.047)$ & 0.050 \\
AST & $1.044(0.981-1.112)$ & 0.176 \\
Total cholesterol & $1.004(0.952-1.059)$ & 0.882 \\
\hline
\end{tabular}

et al. [6] observed a significant increase in the number of large platelets in the AP groups; the median and mean MPV remained at high levels during the acute phase in the mild and severe AP groups. Moreover, the MPV levels showed a downward trend in remission phase in patients with SAP, which supported our results.

In addition, MPV increases during pregancy as a result of hormonal and metabolic changes [24]. Meanwhile, thrombocytopenia is not only a common finding during pregnancy, but also frequent at the onset of AP [25]. Thrombocytopenia can lead to enhanced thrombopoiesis, which increases the quantity of highly reactive large-sized platelets [5]. Thus, these findings may partly explain why there were high MPV levels in our study patients. Akbal et al. [7] also detected higher MPV levels in patients with AP at the time of admission than controls, which was consistent with our results. In addition, our data also showed that the D-dimer was elevated in patients with HTG-APP, which were in agreement with the alterations in MPV. Together, these studies suggest that an elevated MPV facilitates platelet adhesiveness and aggregation, which may lead to a high prothrombotic potential and impairment of pancreatic microcirculation in hyperlipidemia-induced SAP during pregnancy.

There were some limitations to the present study. First, the study population was relatively small. The current study had a very limited number of patients 
because of the rarity of HTG-APP, which could influence the validity of some statistical models, such as regression analysis. Second, owing to ethical reasons, we could not assess the clinical benefits of antiplatelet therapy in this population. It was also difficult to adjust adequately for measurement of patient adherence. Third, this was a single-center, retrospective cohort study; therefore, the results we observed cannot be evaluated definitively. Further multi-center, large-scale, prospective studies are needed to verify the findings of the present study. Although our results may be limited in terms of the sample size and study design, the present study still offers implications for the diagnosis and management of HTG-APP. Given the specific population, we believe our findings may provide new evidence for further studies with larger sample sizes.

\section{Conclusions}

In conclusion, our study demonstrated that the MPV levels were higher in patients with HTG-APP than the control group. In addition, the highest MPV was detected on onset in patients with hypertriglyceridemiainduced SAP during pregnancy. Furthermore, MPV levels decreased in remission in such patients. Thus, MPV could play an important role in the early diagnosis of HTG-APP and may be helpful for evaluating the severity of HTG-APP; however, additional large-scale, prospective studies are required to validate our findings.

\section{Abbreviations \\ ALT: Alanine aminotransferase; AST: Aspartate aminotransferase; HTG- APP: Hypertriglyceridemia-induced acute pancreatitis during pregnancy; HS- CRP: High-sensitivity C-reactive protein; HDL-c: High-density lipoprotein cholesterol; ICU: Intensive care unit; LDL-c: Low-density lipoprotein cholesterol; LDH: Lactate dehydrogenase; MPV: Mean platelet volume; MAP: Mild acute pancreatitis; MASP: Moderately severe acute pancreatitis; SAP: Severe acute pancreatitis; WBC: White blood cells; OR: Odds ratio; $\mathrm{Cl}$ : Confidence interval}

\section{Acknowledgements}

Not applicable.

\begin{abstract}
Authors' contributions
$\mathrm{LHZ}$ designed the study, acquired the data, analyzed the data and drafted the manuscript. XYC designed the study, acquired the data and analyzed the data. JYC and GYJ contributed to the acquirement and analyses of data. YKZ contributed to the design, analyses, interpretation of data and revising the manuscript. All authors have approved the final version to be published.
\end{abstract}

\section{Funding}

The authors declare no funding.

\section{Availability of data and materials}

The datasets used and analyzed in the current study are available from the corresponding author on reasonable request.

\section{Ethics approval and consent to participate}

A written approval letter was obtained from an institutional review board of Hangzhou First People's Hospital (HFPH-IRB 2020KYYLS117-01). The authors declare that all samples involved in the study were collected with the written informed consents were obtained from the parents of infants. And there were no adolescent mothers (under the age of 18 ) in this study.
Consent for publication

Not applicable.

\section{Competing interests}

The authors declare that they have no competing interests.

Received: 20 July 2019 Accepted: 29 September 2020

Published online: 06 October 2020

\section{References}

1. Juneja SK, Gupta S, Virk SS, Tandon P, Bindal V. Acute pancreatitis in pregnancy: A treatment paradigm based on our hospital experience. Int J Appl Basic Med Res. 2013;3(2):122-5.

2. Igbinosa O, Poddar S, Pitchumoni C. Pregnancy associated pancreatitis revisited. Clin Res Hepatol Gastroenterol. 2013;37:177-1.

3. Mali P. Pancreatitis in pregnancy: etiology, diagnosis, treatment, and outcomes. Hepatobiliary Pancreat Dis Int. 2016;15:434-8.

4. Kiss L, Für G, Mátrai $P$, Hegyi $P$, Ivány E, Cazacu IM, Szabó I, Habon T, Alizadeh H, Gyöngyi Z, Vigh É, Erőss B, Erős A, Ottoffy M, Czakó L, Rakonczay $Z \mathrm{Jr}$. The efect of serum triglyceride concentration on the outcome of acute pancreatitis: systematic review and meta-analysis. Sci Rep. 8(1):14096.

5. Adhikari DR, Vankipuram S, Tiwari AR, Chaphekar AP, Satardey RS. Mean platelet volume: a link between thrombosis and inflammation? Curr Pharm Des. 2011;17:47-58.

6. Osada J, Wereszczynska-Siemiatkowska U, Dabrowski A, Dabrowska MI. Platelet Activation in Acute Pancreatitis. Pancreas. 2012;41:1319-24.

7. Akbal E, Demirci S, Koçak E, Köklü S, Başar O, Tuna Y. Alterations of platelet function and coagulation parameters during acute pancreatitis. Blood Coagul Fibrinolysis. 2013;24:243-6.

8. Erbis H, Aliosmanoglu I, Turkoglu MA, Ay E, Turkoglu A, Ulger BV. Evaluating mean platelet volume as a new indicator for confirming the diagnosis of necrotizing pancreatitis. Ann Ital Chir. 2015;86:132-6.

9. Okuturlar Y, Soylu A, Dogan H, Cakmak S, Kirac Utku I, Oztosun B, Akarsu C, Ocak Serin S, Avci A, Kones O, Ozucelik DN, Guzey D, Harmankaya O, Kumbasar A. Mean platelet volume in patients with biliary and non-biliary acute pancreatitis. Int J Clin Exp Pathol. 2015;8:2051-6.

10. World Medical Association. World Medical Association Declaration of Helsinki: ethical principles for medical research involving human subjects. https://www.wma.net/members-area/working-documents/201804_cs_ english/ Accessed 9 Jul 2018

11. Pancreas Study Group CSoG, Chinese Medical Association. Editorial Board of Chinese Journal of Pancreatology, Editorial Board of Chinese Journal of Digestion (2013) Chinese guidelines for the management of acute pancreatitis (Shanghai, 2013). J Clin Hepatol. 29:656-60.

12. Banks PA, Bollen TL, Dervenis C, Gooszen HG, Johnson CD, Sarr MG, Tsiotos GG, Vege SS, Acute Pancreatitis Classification Working Group. Classification of acute pancreatitis-2012: revision of the Atlanta classification and definitions by international consensus. Gut. 2013;62:102-11.

13. Lee J, Goldberg IJ. Hypertriglyceridemia-induced pancreatitis created by oral estrogen and in vitro fertilization ovulation induction. J Clin Lipidol. 2008;2: 63-6.

14. Takaishi K, Miyoshi J, Matsumura T, Honda R, Ohba T, Katabuchi H. Hypertriglyceridemic acute pancreatitis during pregnancy: prevention with diet therapy and omega-3 fatty acids in the following pregnancy. Nutrition. 2009:25:1094-7.

15. Mimidis K, Papadopoulos V, Kotsianidis J, Filippou D, Spanoudakis E, Bourikas G, Dervenis C, Kartalis G. Alterations of platelet function, number and indexes during acute pancreatitis. Pancreatology. 2004;4:22-7.

16. Basaran O, Uncu N, Celikel BA, Aydın F, Cakar N. Assessment of neutrophil to lymphocyte ratio and mean platelet volume in pediatric familial Mediterranean fever patients. J Res Med Sci. 22; 2017.

17. Ranjith MP, DivyaRaj R, Mathew D, George B, Krishnan MN. Mean platelet volume and cardiovascular outcomes in acute myocardial infarction. Heart Asia. 2016:8:16-20.

18. Varol E. Increased thrombopoietin and mean platelet volume in patients with ischemic stroke. Clin Appl Thromb Hemost. 2013;19(3):342-3.

19. Öztürk ZA, Dag MS, Kuyumcu ME, Cam H, Yesil Y, Yilmaz N, Aydinli M, Kadayifci A, Kepekci Y. Could platelet indices be new biomarkers for inflammatory bowel diseases? Eur Rev Med Pharmacol Sci. 2013;17:334-41. 
20. Gasparyan AY, Sandoo A, Stavropoulos-Kalinoglou A, Kitas GD. Mean platelet volume in patients with rheumatoid arthritis: the effect of anti-TNFa therapy. Rheumatol Int. 2010;30:1125-9.

21. Beyazit Y, Sayilir A, Torun S, Suvak B, Yesil Y, Purnak T, Oztas E, Kurt M, Kekilli

$M$, Ibis M. Mean platelet volume as an indicator of disease severity in patients with acute pancreatitis. Clin Res Hepatol Gastroenterol. 2012;36: $162-8$.

22. Lei JJ, Zhou L, Liu Q, Xiong C, Xu CF. Can mean platelet volume play a role in evaluating the severity of acute pancreatitis? World J Gastroenterol. 2017; 23:2404-13.

23. Park Y, Schoene N, Harris W. Mean platelet volume as an indicator of platelet activation: methodological issues. Platelets. 2002;13:301-6.

24. Alemu A, Abebe M, Terefe B, Yesuf M, Melku M, Enawgaw B, Biadgo B. Hematological Indices of Pregnant Women at the University of Gondar Referral Hospital, Northwest Ethiopia: a Comparative Cross-Sectional Study. Clin Lab. 2019; 65(8), doi:https://doi.org/10.7754/Clin.Lab.2019.190115.

25. Vaquero E, Casellas F, Bisbe V, Puig-Diví V, Bermejo B, Guarner L, Malagelada JR. Thrombocytopenia onset in acute episodes of pancreatitis. Med Clin (Barc). 1995;105:334-7.

\section{Publisher's Note}

Springer Nature remains neutral with regard to jurisdictional claims in published maps and institutional affiliations.

Ready to submit your research? Choose BMC and benefit from:

- fast, convenient online submission

- thorough peer review by experienced researchers in your field

- rapid publication on acceptance

- support for research data, including large and complex data types

- gold Open Access which fosters wider collaboration and increased citations

- maximum visibility for your research: over $100 \mathrm{M}$ website views per year

At BMC, research is always in progress.

Learn more biomedcentral.com/submissions 